\title{
Tribute to Angelo Miele, Founding Editor of JOTA
}

\section{Franco Giannessi • David Hull}

Published online: 19 March 2010

(C) Springer Science+Business Media, LLC 2010

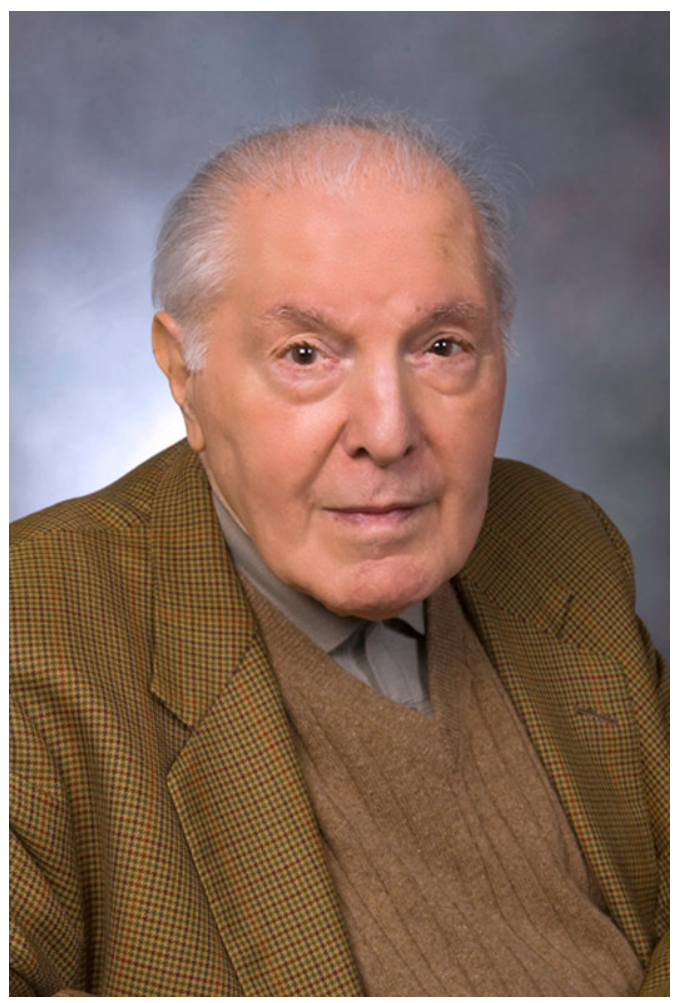

F. Giannessi (凶)

University of Pisa, Pisa, Italy

e-mail: gianness@dm.unipi.it

D. Hull

University of Texas, Austin, USA

e-mail: dghull@mail.utexas.edu 
At the end of 2009, Professor Angelo Miele stepped down as Editor in-Chief of the Journal of Optimization Theory and Applications. The first issue of the journal appeared in 1967; for forty-three years, Professor Miele and his dedicated Associate Editors have been committed to the creation and growth of this world-class journal in optimization.

Professor Miele has had a distinguished career in the development of optimization techniques and their application to aerospace engineering problems. What follows is a brief summary of his accomplishments.

He was born in Formia, Latina, Italy in 1922. His formal education was completed entirely in Italy and culminated in two doctoral degrees: Civil Engineering (1944) and Aeronautical Engineering (1946).

In 1947, he went to Cordoba, Argentina to work in aircraft design at Fabrica Militar de Aviones. He soon discovered that working with incomplete information was not to his liking, so he transitioned to basic research (Instituto Aerotecnico) and teaching. His first positions were as Lecturer at the School of Military Aviation of the Argentinian Air Force (rational mechanics), the School of Aerospace Engineering of the Argentinian Air Force (aircraft design), and the University of Cordoba (applied mechanics).

One of his early research project was to find the trajectory that minimizes the time to climb for a turbojet-powered airplane. Sixty years ago, this was an extremely difficult problem. Analytically, it was a singular optimal control problem about which nothing was known at the time. Numerically, it required a computer solution, which was not possible. However, by making prudent approximations, Professor Miele recognized that Green's theorem could be used to obtain the global minimum for the climb problem as well as for other variational problems of the linear type.

Following a brief stay (1952-55) at Brooklyn Polytechnic Institute as an Assistant Professor designing wind tunnels and teaching flight mechanics, he moved to Purdue University in 1955 as an Associate Professor. Here, he continued his work on optimal trajectories for aerospace vehicles. His projects included optimal thrust programs for rocket-powered aircraft, optimal cruise of a turbojet-powered aircraft, and optimal cruise of a hypervelocity glider. This period of work resulted in a paper on a general variational theory of the flight paths of rocket-powered aircraft, missiles, and satellite carriers. He was promoted to Full Professor in 1958.

In 1959, Professor Miele joined the Boeing Scientific Research Laboratories as Director of Astrodynamics and Flight Mechanics. While there, he made three significant contributions. First, his study of lunar trajectories led to the theorem of image trajectories; given a trajectory in Earth-Moon space, there exist three additional trajectories that are images of the first. The class of image trajectories includes the subclass of symmetric free-return trajectories; these are those image trajectories that intersect the Earth-Moon axis orthogonally. Second, his work on flight mechanics led to the textbook Flight Mechanics (Addison-Wesley, 1962), which was translated into Russian in 1965. Third, during this time, Professor Miele became interested in optimal aerodynamic shapes in the supersonic, hypersonic and free-molecular flow regimes. In 1962, he hosted the international Symposium on Extremal Problems in Aerodynamics which was attended by many important aerodynamicists. While at Boeing, he taught courses in flight mechanics and astrodynamics at the University of Washington in Seattle on a part-time basis. 
In 1964, Professor Miele returned to full-time teaching and research at Rice University. The work on optimal aerodynamic shapes begun at Boeing and continued at Rice became the basis for the edited textbook Theory of Optimum Aerodynamic Shapes (Academic Press, 1965), which was translated into Russian in 1968.

Soon after moving to Rice, Professor Miele recognized the need for an archival journal emphasizing optimization and the interaction between mathematics and applied sciences. Published by Plenum, the first issue of the Journal of Optimization Theory and Applications appeared in 1967. For the last forty-three years, Professor Miele has edited the journal and continued his work in optimization.

From 1967 to 1983, he concentrated on numerical methods, first for optimal control problems and then for mathematical programming problems. Important contributions during this period included the method of particular solutions (MPS) for solving linear two-point and multi-point boundary-value problems, the sequential gradientrestoration algorithm (SGRA) for solving optimal control problems, and the parallel method of particular solutions (PMPS).

After 15 years of algorithm development, Professor Miele began to spend more time on engineering applications. From 1983 to 1993, research projects undertaken included wave identification, optimal aeroassisted orbital plane change manuevers, aeroassisted flight experiment, optimal trajectories for the national aerospace plane, flight in wind shear, and wind identification and detection. During this time, he was appointed to the Foyt Chair at Rice University.

In 1993, Professor Miele formally retired as Professor only to be reappointed as Professor Emeritus and Research Professor. While retirement normally means a reduction in workload, he continued his teaching and research activities at the same pace.

Research projects undertaken after 1993 included the following: minimum fuel transfer of a spacecraft from low Earth orbit to low lunar orbit and return (which numerically verified the theorem of image trajectories); minimum fuel transfer of a spacecraft from low Earth orbit to low Mars orbit and return; conceptual design of next-generation spacecraft; optimal trajectories for supermaneuvering jet fighter aircraft; optimization of ship maneuvers; collision avoidance problems for ships and aircraft; and spacecraft rendezvous problems.

His work on conceptual design associated with the national aerospace plane (NASP) showed that the single-stage-to-orbit (SSTO) concept was not feasible due to limitations of engine specific impulse and airframe structural factor. Hence, he proposed that a two-stage configuration be considered. While no one acknowledged his recommendation, it is a fact that, after a time lag of several years, the NASP program and two subsequent single-stage suborbital and orbital programs were cancelled by the sponsoring organizations.

Professor Miele's research has been sponsored by many organizations. Public support includes the Air Force Office of Scientific Research, Army Ballistic Missile Agency, NACA, NASA Jet Propulsion Laboratory, NASA Langley Research Center, NASA Marshall Space Flight Center, NASA Johnson Space Center, and the National Science Foundation. Private support includes the Air Line Pilots Association, Boeing Company, and Exxon Production Research Company.

Professor Miele's research accomplishments have been recognized in many ways. At the academic level, he has been awarded an Honorary Doctorate of Science from 
Technion-Israel Institute of Technology. At the academy level, he has been elected to the Academy of Sciences of Turin, the International Academy of Astronautics, the National Academy of Engineering of the USA, the Russian Academy of Sciences, and the National Academy of Engineering of Argentina. At the professional society level, he has been awarded the Levy Medal and made Life Fellow of the Franklin Institute; he has been named Fellow and Honorary Fellow of the American Institute of Aeronautics and Astronautics, as well as the winner of the Pendray Aerospace Literature Award and the Mechanics and Control of Flight Award; he has been named Fellow of the American Astronautical Society and winner of the Dirk Brower Award. Also, he has received the Shuck Award of the American Automatic Control Council. There is no award for best Editor-in-Chief. However, if there were, we feel certain that Professor Miele would have won this award as well.

In the mid 1970's, Professor Miele considered returning to his native Italy. He participated in three public competitions for chairs in Italian universities: in mathematics, Analisi Numerica; in electrical engineering, Controlli Automatici; in aerospace engineering, Aeronautica Generale. Even though these are three completely different fields, he won all three competitions simultaneously, a unique feat in the history of the Italian universities. In the end, he decided not to accept any of these positions, much to the benefit of Rice University and the United States.

Several journal issues and conferences have been dedicated to Professor Miele. He has been a member of numerous technical committees and editorial boards and has been invited to give many major addresses and keynote lectures.

At this point of his career, Professor Miele has retired twice, once as a professor and once as an editor-in-chief. The first retirement had no effect on his productivity, and we feel the second will have no effect either. Hence, the Journal of Optimization Theory and Applications is looking forward to many years of association with Professor Miele, both as an advisor and as a contributing author.

\section{Publisher's Note}

Professor Angelo Miele founded the Journal of Optimization Theory and Applications in 1967, to fulfill his vision for a top quality journal focusing on mathematical optimization techniques and their applications to science and engineering. His achievement speaks for itself: the journal has an excellent reputation within its community and is the publication of choice for many. With its sound and steady flow of submissions and a high rejection rate, the journal is highly cited with a long cited half-life of its articles which nicely shows in the now available 5-year impact factor (1.313 in 2008). Professor Miele's untiring dedication and service toward the journal is beyond any appreciation we can express here.

After more than four decades, Professor Miele has retired at the end of 2009 as the Editor-in-Chief of the journal. Springer would like to take this opportunity to thank him for his service to the scientific community. As Founding Editor of the journal, his name will remain tied to the journal as a sign of appreciation. 
We wish Professor Miele the very, very best for the future. For the incoming new Co-Editors-in-Chief, Professor David Hull (Austin, TX) and Professor Franco Giannessi (Pisa), we wish the best of luck and success in taking up the lead in the journal.

Vaishali Damle

Springer 